\title{
ALTOLAGUIRRE Y LORCA: EL NIÑO Y EL DESNUDO*
}

En septiembre de 1930 apareció en Barcelona un número especial del Butlletí de l'Agrupament Escolar dedicado al surrealismo. En este número de la revista, que representó un esfuerzo interesante por integrar algunas voces de la vanguardia de lengua española (Ramón Gómez de la Serna, Giménez Caballero, Rafael Laffón, Rogelio Buendía, etc.) al estado mayor de la vanguardia catalana (Joan Miró, Salvador Dalí, Sebastian Gasch, Masoliver, J. V. Foix, Planells, etc.), el poeta malagueño Manuel Altolaguirre publicó un poema que hasta ahora ha quedado en el olvido. Titulado "Capital", el texto reza como sigue:

\author{
Toda la arquitectura \\ de la ciudad, ya inútil, \\ sólo mantiene firmes \\ los rizos interiores. \\ Escaleras peinadas \\ sobre el cuello y el rostro \\ hasta las altas sienes, \\ hacia el cielo nos llevan. \\ Olvidando los pisos, \\ las ondas, los peldaños, \\ subimos anhelantes \\ buscando a Dios. Subimos \\ hasta la inteligencia. \\ Ya estamos. Resplandece.
}

* La versión original de este artículo fue presentada como ponencia en el Seminario Internacional Surrealismo español: "Poeta en Nueva York" que, organizado por la Universidad Autónoma de Madrid y la Fundación Federico García Lorca, se celebró en Madrid entre el 2 y el 6 de abril de 1990. 
Desde las altas torres:

¡qué aurora sobre el mar!1

Fechado en "Málaga 1930", es decir, en un momento en que era muy difundida la influencia del surrealismo en España, el poema demuestra, sin lugar a dudas, cuán lejos estaba la poética de Altolaguirre tanto de la teoría como de la práctica de este movimiento. Ninguna huella de escritura automática, ningún asomo de elementos oníricos, ninguna violencia, ninguna subversión. En su lugar, lo que algún crítico ha llamado un "conceptismo espiritual" ", mediante el cual el poeta va recreando algo tan íntimo y misterioso como debe de ser un ascenso místico, un auténtico encuentro con Dios.

En 1931, al reseñar la poesía escrita por Altolaguirre durante este periodo, Luis Cernuda habría de señalar la estrecha vinculación que veía entre esta obra y la de los grandes místicos españoles. La voz del malagueño — dijo- es "una voz apasionada, densa y grave, que se remonta sin transición ni intermedio a Juan de la Cruz"'3. En realidad, sí había poetas que de alguna manera servían de puente entre Altolaguirre y el autor del Cántico espiritual; si lo que Altolaguirre valoraba de San Juan de la Cruz era justamente lo que éste tenía de poeta simbolista avant la lettre ( ج saber, su utilización del símbolo para evocar un mundo donde reina el Absoluto), este mismo recurso, aun cuando no manejado con el mismo grado de perfección, lo podía encontrar, por ejemplo, en la obra de quien mejor representaba al simbolismo en España: el poeta J. R. Jiménez; y, efectivamente, la presencia de

1 Altolaguirre, "Capital", Butlletí de l'Agrupament Escolar (Barcelona), Any II, núms. 7-9 (julio-setembre 1930), p. 253. Véase ahora AltolaGuirre, Obras completas, t. 3: Poesía, ed. J. Valender, Istmo, Madrid, 1992, pP. 284-285. El contacto con los andaluces que colaboran en este número (José Luis Cano, Darío Carmona, Rafael Laffón, Rogelio Buendía y Altolaguirre) probablemente lo estableció Dalí, quien pasó el verano de 1930 en Málaga, donde estuvo con Gala, de luna de miel. Las implicaciones de este encuentro de la cultura catalana con la castellana fueron comentadas por otro de los colaboradores, ERnesto Giménez Caballero, "Orientaciones universitarias. Un butlletí de juventud catalana", La Gaceta Literaria (Madrid), núms. 101-102 (15-111-31).

${ }^{2}$ Véase Virorio Bodini, Los poetas surrealistas españoles, trad. Carlos Manzano, Tusquets, Barcelona, 1971, p. 97.

${ }^{3}$ Luis Cernuda, "Málaga-París. Líneas con ocasión de un poeta", Heraldo de Madrid, 10-IX-3I; recogido en Cernuda, Prosa completa, eds. D. Harris y L. Maristany, Barral, Barcelona, 1975, p. 1229. 
Jiménez sí se hizo sentir en la poesía que escribió Altolaguirre durante este periodo.

Pero, de todos modos, Cernuda tenía razón: también resulta innegable la afinidad del malagueño con la poesía del místico del siglo xvı. Como vemos en este poema "Capital", sí hay algo de la misma dinámica: de desprendimiento de los sentidos exteriores ("Toda la arquitectura / de la ciudad, ya inútil, / sólo mantiene firmes / los rizos interiores'); de pasividad en la ascensión ("Escaleras peinadas / sobre el cuello y el rostro / hasta las altas sienes, / hacia el cielo nos llevan"); de ignorancia del proceso mismo mediante el cual el alma asciende a la divinidad ("Olvidando los pisos, / las ondas, los peldaños, / subimos anhelantes / buscando a Dios'); de iluminación al llegar a su encuentro ("Ya estamos. Resplandece"); y, finalmente, de éxtasis, un éxtasis que se experimenta a la vez como muerte ("el mar") y como vida nueva ("la aurora"): "Desde las altas torres: / ¡qué aurora sobre el mar!’.

Pero si Altolaguirre tiene tan poco que ver con el surrealismo, ¿por qué participó en este número especial del Butlletí? La paradoja, que no lo es más que en apariencia, creo que resulta muy instructiva para entender cierto aspecto fundamental de la historia de la poesía española de entreguerras. Porque (para enfocar el asunto desde otro ángulo) ¿cómo es posible que Altolaguirre - siendo muy poco afín al surrealismo- haya guardado tan íntima amistad con poetas como Lorca, Cernuda, Alberti y Aleixandre, y que también haya participado con ellos en tantos proyectos, si éstos estaban tan profundamente identificados con el surrealismo como algunos críticos nos quisieran hacer creer? No descarto la influencia que el surrealismo ejerció en la obra de los cuatro poetas mencionados; sin embargo, creo - al igual que muchos otros críticos- que su compenetración con este movimiento no fue total. Y no fue total, agregaría yo, porque la parte medular de su obra supuestamente "surrealista" estaba encaminada, en realidad, hacia otra cosa: en concreto, hacia el tipo de transcendentalismo poético tan bien ejemplificado por la poesía de su amigo Altolaguirre. Es decir, lejos de estar en desacuerdo con los propósitos perseguidos por estos cuatro poetas durante los años cruciales de 1928-1931, la poesía de Altolaguirre ofrece un punto de referencia inestimable con que identificar el verdadero camino seguido por ellos.

Se trata, me doy cuenta, de una hipótesis algo arriesgada, que, en todo caso, requeriría de una justificación más extensa de 
la que cabría hacer en el espacio de este trabajo. En lo que sigue me limito a proponer cierto parentesco entre este "misticismo" de Altolaguirre y algunos aspectos de la obra supuestamente "surrealista" de Federico García Lorca. Concretamente, propongo demostrar que los dos poetas no sólo comparten un mismo anhelo de trascendencia, sino que en los dos casos este anhelo se expresa, sobre todo, a través de dos motivos fundamentales: el niño y el desnudo ${ }^{4}$. Empecemos, entonces, por identificar al niño y al desnudo en la poesía de Altolaguirre.

1. En los versos de Altolaguirre se observa una dinámica muy especial que en algo se parece a lo que en la obra de San Juan de la Cruz se llama la noche de los sentidos. Para que se logre la unión espiritual, sea con Dios, sea con la mujer amada, el alma tiene que desprenderse de su cuerpo y de los sentidos, hundirse en la ignorancia, en la oscuridad. Esta vía negativa implica o espiritualizar los sentidos, como ocurre en varios de los poemas de Soledades juntas ${ }^{5}$, o simplemente anularlos, como pretende el poeta en los siguientes versos, tomados de uno de los textos publicados en el tercer cuaderno de Poesía:

\author{
¡Cerrad todas mis puertas! \\ Que este dolor se encuentre \\ desconocido, inmóvil; \\ que apague mis sentidos \\ y todo se haga noche: \\ mi carne, el aire, todo; \\ que mi dolor oscuro \\ no pueda tener límites; \\ que para mí no queden \\ ni luces ni alegrías (p. 59) ${ }^{6}$.
}

${ }^{4}$ En el caso de Lorca, ambos motivos han sido objeto de importantes estudios por parte de la crítica. Véase, por ejemplo, Rafael Martínez NADAL, "El niño en la obra de García Lorca", "El Público". Amor y muerte en la obra de Federico García Lorca, ed. amp. e ilustr., Hiperión, Madrid, 1988, pp. 257-276; y J. Rubia Barcia, "Ropaje y desnudez de El público", $C u H$, 1986, núms. 433/434, 385-397.

${ }^{5}$ Véanse, por ejemplo, los poemas "¿Qué sola estabas por dentro!", “QQué música del tacto... !", "El alba" y "Al mediodía”, de Soledades juntas, Editorial Plutarco, Madrid, 1931; recogidos en Altolaguirre, Obras completas, t. 3: Poesía, ed. cit., pp. 192-193, 208, 286, 287.

${ }^{6}$ En Poesía, Málaga, 1930, núm. III, s. p. Todos los poemas que en adelante se citan se dieron a conocer o en los tres primeros números de Poesía 
"Negar tus deseos - sentencia San Juan de la Cruz- y hallarás lo que desea tu corazón"' poeta aspira a llegar al centro de su alma, donde ha de celebrarse la unión con la divinidad. Concebido en términos neoplatónicos, este ascetismo significa para Altolaguirre un proceso de desnudamiento espiritual que le permitirá acceder, más allá de las formas de lo visible, al mundo invisible de las ideas. Noción que queda perfectamente resumida en uno de los poemas de la segunda entrega de Poesía, posteriormente titulado "Pétalos". Las distintas formas que el ser va adquiriendo en el tiempo son otros tantos "pétalos" que el poeta va quitando para llegar así a la esencia de ese ser, a su "alto perfume libre":

Mírate en un espejo y luego mira
estos retratos tuyos olvidados,
pétalos son de tu belleza antigua,
y deja que de nuevo te retrate
deshojándote así de tu presente;
que cuando ya invisible sólo seas
alto perfume libre: alma y recuerdo,
junto al tallo sin flor pondré caídos
estos retratos tuyos para verte
como aroma subir y como forma
quedar abandonada en este suelo (pp. 179-180).

El ser vive disperso en el tiempo, pero, mediante este desprendimiento, puede salvarse, puede recuperar su "centro permanente", su alma, que, ya separada de su cuerpo (así como de las distintas formas que le han dado expresión), sube "como aroma" al Absoluto, a la esfera pura de las ideas.

Ahora, siguiendo un procedimiento caro tanto a los románticos como a los simbolistas, Altolaguirre identifica esta salvación con la figura del niño. Recuperar el "centro permanente" perdido es recuperar la propia infancia: esa forma de vivir el mundo como si el tiempo no existiera. Esto se ve claramente ejemplifica-

(Málaga, 1930) o en el segundo libro de poemas de Altolaguirre, Ejemplo (Litoral, Málaga, 1927). Ninguna de estas publicaciones lleva paginación. El número que figura entre paréntesis al final de cada texto remite al lector a la página correspondiente de mi edición de la Poesía de Altolaguirre arriba señalada.

7 San Juan de la Cruz, "Dichos de luz y amor. Avisos y sentencias espirituales", en José Luis Aranguren (ed.), Sun Juan de la Cruz, Júcar, Madrid, 1973, p. 161. 
do en otro poema sin título recogido en el tercer cuaderno de Poesia:

\author{
¿Qué error! Me parecía \\ que aquel lejano niño \\ se estaba yendo para siempre, \\ que aquel alegre joven distraído \\ se alejaba también. ¡Mentira todo! \\ El joven está en mí \\ como un hombre vestido de otro hombre \\ y de otro, y de otro..., externamente \\ llegando hasta la última envoltura, \\ esta piel mía de ahora; \\ o siendo abrigo de otros cuerpos \\ hasta llegar al niño que yo era \\ que es centro de mi vida, \\ que está en mí \\ como si estuviera en una inmensa flor \\ que al deshojarse lo mostrara \\ desnudo y sonriente (pp. 111-112).
}

La relación de este texto con el poema anterior resulta evidente. Si para Altolaguirre unirse con el Absoluto es también, y sobre todo, reunirse con su propia niñez, con las fuerzas creadoras, con el impulso de vida nueva, que todo niño trae consigo, esta reintegración se logra "deshojando" todas las formas externas -llámense ropas o pétalos - hasta llegar al niño: es decir, hasta dejar al alma desnuda.

En estos dos poemas la trascendencia anhelada no parecería ofrecer ningún problema para su realización. Y, sin embargo, en muchos de los versos que el poeta escribiera por estas fechas, la nota predominante es la de frustración. Lo es, por ejemplo, en "Desnudo", uno de los poemas del segundo cuaderno de Poesía. Ahí, el esfuerzo que hace el niño por "asomarse", por "nacer", se expresa a través del tópico neoplatónico de la búsqueda del alma por escapar de la cárcel que es su cuerpo; pero, aquí, a diferencia de lo que ocurre en los otros poemas citados, la tentativa finalmente resulta vana:

Eras cárcel de música, de la música presa que intentaba escapar en cada gesto tuyo, 
pero que no podía salir

y se asomaba como un niño

a los cristales de tus ojos claros (pp. 201-202).

La potencialidad de vida nueva se frustra: frustración que se expresa en la imagen del niño asomado a los cristales. El vidrio hace transparente la presencia del niño, pero también lo aísla de quien lo busca; es decir sólo exaspera el deseo. Algo de la misma dinámica lo encontramos en un poema de Ejemplo (1927), en que el cristal se asocia con el proceso mismo de rememoración: la memoria evoca al niño, pero el poeta tiene conciencia de que esta imagen es sólo esto: un recuerdo y no una realidad. Y la conciencia que tiene de esta distinción finalmente lo separa de la experiencia que anhela:

De cristal las paredes, el recuerdo descubriendo distancias y posturas fabricó. Decapitado cuerpo de aire ${ }^{8}$, hueco traje de ausente en el ropero, a mi memoria dieron el motivo.

Vi el mar tras las paredes. Por la playa mi infancia y mi ascendencia de la mano (p. 260).

Lo que es especialmente revelador de este fragmento es que, a la vez que evoca la frustración a que puede llevar la memoria, también identifica la angustia de donde procede este tipo de aspiración: una angustia que consiste en vivir en un mundo de formas insustanciales, en que la única realidad parecería ser un "hueco traje de ausente en el ropero". Lo cual nos devuelve a la binomia "vestidos" y "desnudo" que vimos en el poema "iQué error! Me parecía". Para que pueda "asomarse" a la vida nueva, el alma tiene que "desnudarse" de todos estos "huecos trajes" "de ausente" que corresponden a su vida mortal. Como nos enseña su "Canción de alma", una de las composiciones más famosas de Altolaguirre, publicada en la segunda entrega de Poesía, el niño es inseparable del desnudo:

${ }^{8}$ Esta imagen de mutilación ("Decapitado cuerpo de aire") demuestra que Altolaguirre sí estaba familiarizado con el lenguaje del surrealismo, y desde una fecha relativamente temprana. Seguramente, otros ejemplos del empleo de imágenes surrealistas podrían rastrearse en su poesía. Sin embargo, se trata de contaminaciones muy esporádicas en un discurso que, como sugerí al principio, sigue una dinámica muy distinta a la del surrealismo. 
¡Ven, que quiero desnudarme!

Ya se fue la luz y tengo cansancio de estos vestidos.

¿Quítame el traje! Que crean

que he muerto porque desnuda

mientras me velan el sueño

descanso toda la noche;

porque mañana temprano

desnuda de mi desnudo

iré a bañarme en un río

mientras mi traje con traje

lo guardarán para siempre.

Ven muerte, que soy un niño

y quiero que me desnuden, que se fue la luz y tengo

cansancio de estos vestidos (p. 65) ${ }^{9}$.

Para que el niño se integre plenamente al espacio espiritual que le corresponde (es decir, para que el alma efectivamente nazca a una vida nueva), la muerte tiene que intervenir: una muerte que es un desprendimiento de todas las formas mortales, de todos los trajes y vestidos. El niño, para llegar a serlo, tiene que convertirse también en el desnudo.

2. Volviendo ahora a Federico García Lorca, veamos cómo también en varios de los poemas de Poeta en Nueva York hay un angustiado anhelo de trascendencia que se expresa en términos de una búsqueda del niño. Ésta es la temática principal, por ejemplo, de "1910 (Intermedio)", "Tu infancia en Menton", "Poema doble del Lago Edén", “El niño Stanton" y "Niña ahogada en

${ }^{9}$ Como me ha hecho ver la profesora Nadine Ly, en un comentario que le agradezco, este poema tiene ciertos paralelismos con otro de Pedro Salinas, "Para vivir no quiero", de La voz a ti debida (Signo, Madrid, 1933): "Quítate ya los trajes, / las señas, los retratos; / yo no te quiero así, / disfrazada de otra, / hija siempre de algo. / Te quiero pura, libre, / irreductible: tú". Y más adelante: "Iré rompiendo todo / lo que encima me echaron / desde antes de nacer. / Y vuelto ya al anónimo / eterno del desnudo, / de la piedra, del mundo, / te diré: "Yo te quiero, soy yo»". Véase Salinas, Poesías completas, ed. S. Salinas de Marichal (2a ed., Barral, Barcelona, 1974), p. 243. Sin embargo, como la profesora Ly también reconoce, entre los dos textos hay diferencias de énfasis y de sentido. Mientras que el poema de Salinas (como la colección entera a la que pertenece) gira alrededor de un amor humano plenamente gozado, el de Altolaguirre va más bien en busca de un más allá espiritual, apenas intuido. 
el pozo (Granada y Newburg)". Por otra parte, la misma preocupación aflora en otros poemas que, aunque no recogidos en Poeta en Nueva York, también datan de esta época: en el soneto "Adán", por ejemplo, o en ese extraordinario poema que desenterró Rafael Martínez Nadal, "Infancia y muerte". A pesar de sus muchas diferencias formales, lo que caracteriza a todos estos poemas es la escisión que se proyecta en ellos entre dos conciencias: la del adulto y la del niño. Para el adulto la recuperación de la conciencia del niño representaría una forma de superar esta escisión, de recuperar la propia integridad. Pero en todos los casos, el intento por lograr esta reintegración se frustra. $Y$ de ahí la angustia del poeta, que no soporta el "hueco"' (véase el "Nocturno del hueco") a que se reduce su vida sin esta posibilidad de trascendencia. "Para buscar mi infancia ¡Dios mío!", escribe, por ejemplo, en "Infancia y muerte",

comí naranjas podridas, papeles viejos, palomares vacíos.

Y encontré mi cuerpecito comido por las ratas en el fondo del aljibe con las cabelleras de los locos ${ }^{10}$.

La muerte anunciada en el título de este poema se refiere, desde luego, a la anulación de esa potencialidad de vida nueva que el poeta presiente, pero que no logra desencadenar; el niño, al no ser liberado, se asfixia, se ahoga o, como en este poema, es "comido por las ratas". Pero la muerte aquí también tiene otra connotación, ya que se refiere, a la vez, al proceso de mortificación a que tiene que someterse el poeta a fin de lograr transformarse como quiere. Es decir, el poeta se encuentra arrinconado entre dos formas de muerte: si no logra unirse con el niño, algo vital en él se muere; pero, para lograr esa unión, igualmente tiene que pasar por una "muerte".

Las "naranjas podridas", los "papeles viejos" y los "palomares vacíos" deben entenderse, según creo, en el contexto de esta mortificación. Porque de lo que se trata es de ir excavando

${ }^{10}$ Sigo aquí la transcripción del poema publicada por RafaEL Martínez NaDal en Trece de Nieve (Madrid), 2a. época, 1976, núms. 1/2, p. 180. Sobre este poema, véase, en el mismo número de la revista, los ensayos de María Zambrano, "El viaje: infancia y muerte", y de José Ángel Valente, "Pez luna", pp. 181-190 y 191-201, respectivamente. También resulta muy instructivo el análisis que ofrece Miguel García-PosAda, "Infancia y muerte", en Andrés Soria Olmedo (ed.), Lecciones sobre Federico García Lorca, Comisión Nacional del Cincuentenario, Granada, 1986, pp. 181-193. 
y escombrando, por debajo de los desechos que son las formas mortales que asume la vida, hasta lograr llegar a su esencia. Y es en este proceso de mortificación, de desprendimiento de formas muertas, donde vemos la íntima relación que existe, en Lorca no menos que en Altolaguirre, entre el niño y el desnudo. De hecho, de lo que se queja Lorca, una y otra vez en sus poemas neoyorkinos, es de verse obligado a habitar un mundo conformado únicamente de trajes y de huecos, de formas sin esencia o, como él dice (coincidiendo en esto con Altolaguirre), " sin desnudo". En "1910 (Intermedio)", por ejemplo, escribe:

No preguntarme nada. He visto que las cosas cuando buscan su curso encuentran su vacío. Hay un dolor de huecos por el aire sin gente $y$ en mis ojos criaturas vestidas $;$ sin desnudo! ${ }^{11}$

El desnudo se identifica con el niño, pero sólo se confunde completamente con él en la muerte. Mientras no sobrevenga la muerte, podríamos decir que existe entre ellos una relación más bien de causa y efecto: cuanto más desprendimiento y desnudez espiritual, más grande (potencialmente hablando) es la fuerza con que el niño, o la vida nueva, se afirma. Característicamente, en Poeta en Nueva York, esta relación entre las dos partes de la dinámica se simboliza en la pasión de Cristo, por un lado, y en el nacimiento del Niño Jesús, por otro: contraposición que tiene sus reverberaciones en poemas como "Iglesia abandonada (Balada de la Gran Guerra)", "Navidad en el Hudson", "Nacimiento de Cristo" y "Crucifixión" 12 .

Esta simbología cristiana obviamente fue muy importante para Lorca, porque también la introduce en otro proyecto que emprendió por estas fechas, su drama El público. Aquí la imagen del niño ha desaparecido casi por completo, pero sí interviene la otra parte de la dinámica, encarnada en la figura del Desnudo Rojo, quien, en una obvia alusión a la Pasión de Cristo, se presenta "coronado de espinas azules"'13. La desaparición del niño

11 Federico García Lorca, “1910 (Intermedio)”, Poeta en Nueva York, ed. M. Hernández, Fundación Banco Exterior, Madrid, 1987, p. 28.

12 Para un estudio de esta identificación de Lorca con Cristo, véase Derek Harris, García Lorca: Poeta en Nueva York, Tamesis, London, 1978; y Eutimio MarTínez, Federico García Lorca, heterodoxo y mártir. Análisis y proyección de la obra juvenil inédita, Siglo XXI de España Editores, Madrid, 1986.

${ }^{13}$ Federico García Lorca, El público, ed. M. C. Millán, Cátedra, 
es sintomática de la enajenación que Lorca retrata en la obra. En lugar de integrarse a esa permanente fuente de vida nueva, de formas nuevas, que el niño simboliza, la mayoría de los personajes se enajenan. $O$ se niegan a reconocer que la vida cambia y se esconden tras una máscara, tras una identidad fija e inmutable; o, sensibles a la naturaleza cambiante de la realidad, van quitando "trajes" y "vestidos" en un esfuerzo por descubrir la forma auténtica o esencial de los seres, sea de sí mismos o de los demás: esfuerzo inútil, porque esta forma auténtica no existe: de hecho, lo extratemporal no es forma, sino algo anterior a ella: potencialidad de vida nueva, energía creadora, amor. Es decir, de una u otra manera, la mayoría de los personajes intentan reducir la naturaleza proteica de la vida a algo fijo y uniforme: propósito que, desde luego, sólo puede desembocar en la anulación del principio vital.

El único que no participa en esta enajenación es el Desnudo Rojo, quien, como Cristo en la Cruz, asume la propia muerte como condición para integrarse a ese fluir. Es decir, en lugar de detener las transformaciones que constituyen la vida, mediante la muerte de su propia individualidad aspira a fundirse con la energía - llámese espíritu, pasión o amor- de donde proceden todas las formas que va asumiendo la vida. Esto es lo que se propone (según se deduce de la acción del drama), para, con su agonía, salvarse a sí mismo y a los demás. Empresa heroica, pero que aquí, al igual que en los poemas de Poeta en Nueva York, parece frustrarse. Al menos, el marco netamente paródico en que se desarrolla esta nueva Pasión de Cristo, no permite guardar muchas ilusiones en cuanto a la eficacia del sacrificio:

DESNUDO: Yo deseo morir. ¿Cuántos vasos de sangre me habéis sacado?

ENFERMERO: Cincuenta. Ahora te daré la hiel, y luego, a las ocho, vendré con el bisturí para ahondarte la herida del costado.

DESNUDO: ¿Es la que tiene más vitaminas?

ENFERMERO: Sí.

Y luego, un poco más adelante:

DESNUDO: ¿Cuánto falta para Jerusalén?

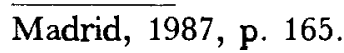


ENFERMERO: Tres estaciones, si queda bastante carbón ${ }^{14}$.

Tal y como se desarrolla la acción de la obra, todo parecería indicar que este tren nunca llega a su destino. Por otra parte, ninguno de los demás personajes presta la más mínima importancia a la agonía del Desnudo. Así el sacrificio se presenta a la vez como terriblemente necesario y como vano o inútil.

3. Para resumir, no ha sido mi propósito demostrar ninguna influencia de Altolaguirre en Lorca (o viceversa) ${ }^{15}$, ni tampoco proponer una identificación absoluta entre ellos. Salta a la vista que son dos poetas muy distintos entre sí. Las dos imágenes cuyas huellas hemos ido siguiendo - el niño y el desnudo- tienen un desarrollo más rico y complejo, aunque no por eso más intenso, en la obra del granadino que en la del malagueño. (Quizás porque dan expresión a una aguda crisis de fe, hay en Lorca, sobre todo, un tono más violento y angustiado, así como un mayor dramatismo, frente a la relativa seguridad con que Altolaguirre expone su propia visión religiosa.) Por otra parte, tampoco he querido establecer una identificación absoluta entre estos dos poetas y San Juan de la Cruz, sino más bien sugerir que, en los años 1927-1931, el místico del siglo Xvi fue un modelo más importante para ellos que el surrealismo. Aunque sobre este último punto, seguramente habría mucho más que decir.

Marcar los límites exactos de la influencia del surrealismo en Lorca no sería fácil; entre otras razones, porque tampoco sería fácil definir al movimiento en sí. ¿Se caracteriza por su escritura, sea o no automática? ¿Por su actitud política o moral? ¿Por sus declaraciones teóricas? ¿Por la puesta en práctica de estas teorías?... Los críticos no se han puesto de acuerdo al respecto y sería difícil que lo hicieran ${ }^{16}$. En el contexto de la presente dis-

${ }^{14}$ El público, pp. 165-166.

${ }^{15}$ Es posible que esta confluencia de ideas y propósitos se deba, en parte, a la influencia en ambos de Emilio Prados, quien, tras su estancia en Freiburg en 1922-1923, tal vez fuera el primero de los poetas del 27 en buscar este camino. En todo caso, habría que tomar en cuenta algo que iba a señalar AltolaguirRe en 1940, que "los jóvenes poetas españoles nunca estábamos solos; me atrevería a decir que, a veces, trabajábamos en colaboración. [Al hablar] de este hecho, la crítica poco conocedora de la vida de nuestro grupo atribuía a semejanza de temperamento lo que era producto de una coincidencia vital'". Véase su prólogo a Ángel Lázaro, Antología poética, La Verónica, La Habana, 1940.

${ }^{16}$ La discusión ha sido muy larga y detallada. Además del libro clásico de 
cusión, tendríamos que empezar por reconocer que también la teoría surrealista encerraba cierto elemento místico: el deseo de reconciliar "estos dos estados, aparentemente tan contradictorios, que son el sueño y la realidad" 17 implicaba igualmente una búsqueda del Absoluto. Pero entre lo que proponían Lorca y Altolaguirre, y lo que proponían Bretón y sus colegas, había una diferencia fundamental: aquélla que media entre un estado mental irracional, provocado racionalmente, y un estado de alma, producto de un ascetismo espiritual. Porque, a diferencia de lo que ocurre con los surrealistas, para los poetas españoles la experiencia de trascendencia no puede provocarse voluntariamente. El poeta que busca liberarse de las limitaciones del "campo imaginativo", dice Lorca en su conferencia "Imaginación, inspiración, evasión"',

deja de soñar y deja de querer. Ya no quiere, ama. Pasa de la 'imaginación', que es un hecho del alma, a la inspiración, que es un 'estado del alma'. Pasa del análisis a la fe. Aquí ya las cosas son porque sí, sin efecto, ni causa explicable. Ya no hay términos ni límites, admirable libertad ${ }^{18}$.

Aunque esta "admirable libertad" fue también aspiración suya, los surrealistas creían que la pasividad que se requería para acceder a este estado podía provocarse mecánicamente; de ninguna manera la planteaban como consecuencia de un ascesis espiritual. Así, la actitud finalmente voluntariosa e intelectual de los surrealistas no les permitió, tal y como hubieran querido, abandonar el querer y entrar al auténtico trance de amar: les faltaba la humildad necesaria. Y de ahí las discrepancias que expresara Lorca en su conferencia con respecto a la forma en que los

Bodini ya señalado, convendría destacar los siguientes títulos: C. B. MoRris, Surrealism and Spain. 1920-1936, Cambridge University Press, London, 1972; PAUl Ilie, Los surrealistas españoles, Taurus, Madrid, 1972; Víctor G. DE LA Concha (ed.), El surrealismo, Taurus, Madrid, 1982; Jesús García Gallego (ed.), Surrealismo. El ojo soluble, Litoral, Málaga, 1987; C. B. Morris (ed.), The surrealist adventure in Spain, Dovehouse Editions, Ottawa, 1991 (Ottawa Hispanic Studies, 6); GABriele Morelli (ed.), Treinta años de vanguardia española, El Carro de la Nieve, Sevilla, 1991.

17 André Breton, Manifiesto del surrealismo (1924), en Manifiestos del surrealismo, trad. Andrés Bosch, Guadarrama, Barcelona, 1980, p. 30.

${ }^{18}$ Federico García Lorca, "Imaginación, inspiración, evasión", Conferencias II, ed. C. Maurer, Alianza, Madrid, 1984, p. 17. 
surrealistas buscan la trascendencia. "Esta evasión poética puede hacerse de muchas maneras", dice ahí:

El surrealismo emplea el sueño y su lógica para escapar. En el mundo de los sueños, el realísimo mundo de los sueños, se encuentran indudablemente normas poéticas de emoción verdadera. Pero esta evasión por medio del sueño o del subconsciente es, aunque muy pura, poco diáfana. Los latinos queremos perfiles y misterio visibles. Forma y sensualidades ${ }^{19}$.

Finalmente, en el Lorca de Poeta en Nueva York (lo mismo que en el Altolaguirre de Soledades juntas, el Cernuda de Los placeres prohibidos, el Alberti de Sobre los ángeles o el Aleixandre de Espadas como labios) hay una espiritualización de los datos sensoriales que está casi completamente ausente en el surrealismo francés: una espiritualización que da pie a la "forma" y a las "sensualidades" defendidas aquí por Lorca.

Al hablar de esta aspiración mística de Altolaguirre y Lorca, habría que recordar, por otra parte, que el simbolismo también se concebía como una búsqueda del Absoluto. Y en este sentido, habría que reconocer como un antecedente importante de la actitud de Lorca y Altolaguirre la poesía "desnuda" de uno de los máximos exponentes del simbolismo en España, J. R. Jiménez. En Jiménez se encuentran no sólo estos dos motivos fundamentales del niño y el desnudo, sino también una misma devoción por San Juan de la Cruz, a quien el poeta de Moguer identifica plenamente, por cierto, con los ideales del movimiento simbolis$\mathrm{ta}^{20}$. La deuda de los dos jóvenes poetas para con su antiguo maestro, sin duda, fue grande. Y, sin embargo, tampoco convendría exagerar el caso. A fin de cuentas, el absoluto que se proponía un simbolista como Jiménez se concebía, sobre todo, como fruto de una sensibilidad estética e intelectual; Lorca y Altola-

${ }^{19}$ Op. cit., pp. $20-21$.

${ }^{20}$ En sus Conversaciones con J: $R$. Jiménez, Ricardo Gullón recoge, entre otras, la siguiente declaración del poeta de Moguer: "En el simbolismo los místicos españoles influyeron tanto como Poe y tanto como Wagner y la música wagneriana. La poesía de San Juan circulaba por Francia en la traducción del monje de Solesmes, en manuscritos, incluso desde antes que hubiera impresa edición española...". Apud ANTONIO BLANCH, La poesía pura española. Conexiones con la cultura francesa, Gredos, Madrid, 1976, p. 239. En la misma página Jiménez también relaciona el simbolismo con la poesía arábigo-andaluza, punto que también merecería, sin duda, ser tomado en cuenta en la presente discusión. 
guirre, en cambio, aunque cercanos a él en muchos aspectos, tenían una actitud más dinámica, más vital.

No: si hay que buscar la verdadera afinidad de Altolaguirre y Lorca ( las más modernas como el surrealismo y el simbolismo), hay que buscarla en el romanticismo. Y, más concretamente, en esa veta del romanticismo representada en el Norte de Europa por profetas y visionarios como Hólderlin, Goethe, Nietzsche, Novalis, Coleridge y Blake. Éstos fueron, desde luego, los verdaderos antecedentes del simbolismo francés. También fueron, junto con Rimbaud y Lautréamont, algunos de los "dioses" y precursores más importantes del surrealismo. Así, al remontar la tradición poética moderna hasta descubrir sus raíces en el romanticismo nórdico, los poetas españoles seguramente encontraron mucho estímulo, y mucho eco, tanto en los surrealistas como en los simbolistas.

Sin embargo, para los poetas españoles sí había algo decisivo que distinguía al romanticismo de los otros movimientos posteriores (sobre todo, del surrealismo), y era el elemento religioso. A la vinculación entre poesía y amor que los surrealistas, a su vez, volverían a celebrar, los románticos habían agregado un tercer elemento: la religión. Para ellos no había diferencia entre experiencia poética y visión religiosa, como tampoco la había entre esta visión y el amor. (Piénsese, por ejemplo, en un Blake, un Hólderlin o un Novalis.) Los surrealistas, en cambio, por mucho que hablaran de lo "sagrado", partían de una serie de presupuestos que, en realidad, eran más bien científicos que religiosos (me refiero, desde luego, a las teorías tanto de Freud como de Marx).

Como espero haber indicado (al menos en el caso de Lorca y Altolaguirre), para los poetas españoles era fundamental la vinculación romántica del amor y de la poesía con la visión religiosa. De ahí, según creo, sus discrepancias con la actitud científica e intelectual de los surrealistas franceses. Y de ahí también, por otra parte, su reivindicación de San Juan de la Cruz, poeta cuyo ejemplo durante estos años (1928-1931) fue decisivo. No por nada dedica Altolaguirre el primero de sus cuadernos de Poesía a la obra del carmelita. Y tampoco es casual el que Lorca, al desarrollar su teoría romántica de la inspiración en la citada conferencia, mencione a San Juan de la Cruz como el máximo ejemplo de un poeta inspirado. Eran dos formas de apropiárselo; porque de eso se trataba: no de convertirse ellos en dos místicos 
ortodoxos del siglo xvi, sino de adaptar a San Juan a su propia estética, de convertirlo en el poeta romántico que, en ese sentido, España nunca había tenido ${ }^{21}$.

Desde luego, como dije al principio, esta hipótesis necesitaría una justificación mucho más amplia de la que he podido desarrollar aquí. Pero, en todo caso, a través de los breves comentarios que he hecho, espero haber demostrado que es una posibilidad digna al menos de tomarse en cuenta.

JAMES VALENDER

El Colegio de México

${ }^{21}$ Desde luego, no fue ésta la única lectura interesada que los poetas del 27 hubieran hecho de los clásicos españoles. Otro tanto cabría decir de su famoso homenaje a Góngora, escritor barroco a quienes ellos convirtieron en poeta cubista avant la lettre. En 1933 Altolaguirre volvería a hacer lo mismo en su biografía de Garcilaso, al convertir al poeta renacentista en una figura netamente romántica. $\mathrm{Y}$ huellas de la misma actitud también pueden rastrearse, según creo, hasta en un libro en apariencia tan objetivo como Lenguaje y poesía de Jorge Guillén: un volumen en donde, al colocar el capítulo sobre San Juan de la Cruz después del capítulo sobre Góngora, y justo antes del que dedica a Bécquer, Guillén parece insinuar o que la obra de San Juan le resulta finalmente más contemporánea que la de Góngora, o que les sirvió a los poetas de su generación como puente entre el cubismo neogongorino de los años 20 y el neorromanticismo becqueriano de los años 30; o, quizás, ambas cosas a la vez. Otro testigo de la época, José MoRENo Villa, en su libro Leyenda a

(El Colegio de México, México, 1944) coincide en resaltar la importante influencia que San Juan de la Cruz ejerciera en los poetas del 27, una influencia, según él, mucho más importante, a la larga, que aquella que ejerciera Góngora. 